intra-articular injections of steroids have an important place in the overall management of patients suffering from both types of chronic arthritis. These injections should not, however, be given in a predetermined course of treatment; and the interval between injections should not be less than four weeks. Before any repeat injection is given, the doctor should carefully appraise the effect achieved and the state of the joint.

Clinicians following this balanced advice will do much good to their reputation and little harm to the patient. The case for local corticosteroid injections in rheumatoid arthritis is well substantiated. In osteoarthrosis a more rational approach may be to infiltrate tender areas around the joint intralesionally, unless there is an obvious reactive synovitis secondary to the degenerative condition, when intra-articular therapy may help.

${ }^{1}$ Hollander, J L, et al, fournal of the American Medical Association, 1951, $147,1629$.

2 Duff, I F, Postgraduate Medicinc, 1956, 19, 577.

3 Chandler, G N, Wright, V, and Hartfall, S J, Lancet, 1958, 2, 659.

1 Van Pelt, R W, fournal of the American Veterinary Association, 1968, 153, 446.

Miller, J H, White, J, and Norton, $\mathrm{T} \mathrm{H}$, fournal of Bone and foint Surgery, $1958,40 B, 636$.

"Wright, V, et al, Annals of the Rheumatic Diseases, 1960, 19, 257

Wright, V, Annals of the Rheumatic Diseases, 1964, 23, 389.

Shah, K D, and Wright, V, Annals of the Rheumatic Diseases, 1967, 26, 316.

${ }^{9}$ Chandler, G N, and Wright, V, Lancet, 1958, 2, 661.

1" Chandler, G N, et al, British Medical fournal, 1959, 2, 952.

1 Johnson, R L, Smyth, C J, and Holt, G W, Arthritis and Rheumatism, 1959, 2, 224 .

1: Sweetnam, I) R, Mason, R M, and Murray, R O, British Medical fournal, 1960, 1, 1392.

${ }^{13}$ Steinberg, C L R, Duthic, R D, and Piva, A E, Fournal of the American Medical Association, 1962, 181, 851.

14 Zachariae, L, Acta ()rthopaedica Scandinavica, 1965, 36, 127

${ }^{15}$ Miller, W ' $\mathrm{W}$, and Restifo, R A, Radiology, 1966, 86, 653.

${ }^{16}$ Alarcón-Segovia, D, and Ward, L C, Arthritis and Rheumatism, 1966, 9, 443.

17 Bentley, G, and Goodfellow, J W, Fournal of Bone and foint Surgery, 1969, 51B, 498.

1* Denko, C W, and Bergenstal, D M, Endocrinology, 1961, 69, 769.

${ }^{19}$ Mankin, H P, and Conger, K A, fournal of Bone and foint Surgery, 1966, 48A, 1383 .

"Moskowitz, R W, et al, Arthritis and Rheumatism, 1970, 13, 236.

21 Silberberg, M, Silberberg, R, and Hasler, M, Archives of Pathology, 1966, 82, 569.

2.2 Salter, R B, Gross, A, and Hall, J H, Canadian Medical Association fournal, 1967, 97, 374 .

23 Anastassiades, T, and Dziewiatkowski, D, fournal of Laboratory and Clinical Medicinc, 1970, 75, 826.

2.4 Poswillo, D, Oral Surgery, 1970, 30, 161

25 Gibson, T, et al, British Association for Rheumatology and Rehabilitation, Annual General Meeting, London, 1976.

${ }^{26}$ Balch, H W, et al, Rheumatology and Rehabilitation, 1977, 16, 137.

\section{Umbilical cord prolapse}

Prolapse of the umbilical cord occurs in about four deliveries in every thousand. ${ }^{1}$ Though it is an infrequent complication, the high associated fetal mortality rate gives it unusual importance.

The primary cause of cord prolapse is incomplete filling of the pelvic cavity by the presenting part of the fetus at the time the membranes rupture. Non-engagement of the presenting part, commonly associated with an abnormal presentation, was a factor in $83^{\circ}{ }_{0}$, of 424 cases reported by Cushner. ${ }^{1}$ The risk of cord prolapse is greatest when the fetal lie is transverse or there is a compound presentation. Numerically, however, breech presentation is the most common single cause of these accidents, accounting for $40-50^{\circ} \%$ of all cases. The risk is three times greater when the fetal legs are flexed than when they are extended. ${ }^{2}{ }^{3}$ Other recognised factors include prematurity, multiple pregnancy, long cord, ${ }^{45}$ polyhydramnios, and fetal hypotension. ${ }^{6}$ There is no uniform agreement on whether or not amniotomy is relevant. Despite the increased frequency of induction in recent years the incidence of prolapsed cord has remained fairly constant. ${ }^{2}$ In one series prolapse occurred twice during 1000 labours induced by amniotomy but five times during 1000 matched control spontaneous labours ${ }^{7}$; in contrast in another study there were four episodes of prolapsed cord after 1000 amniotomies but only two in 1000 matched control patients with spontaneous labours. ${ }^{8}$ Provided that the usual precautions are observed the frequency of prolapse seems unlikely to be more than marginally increased by amniotomy.

Immediate delivery of the fetus remains the cornerstone of treatment. Attempts to replace the prolapsed cord have no place in modern obstetrics. Rapid expert assessment is necessary to determine the best course of action. If the fetal heart beat is present and the fetus is sufficiently mature to be viable then immediate delivery is mandatory. Provided the cervix is fully dilated and vaginal delivery can be achieved without delay-and without undue trauma-then this may be the preferable course of action. If not, then the fetus should be delivered by immediate caesarean section. Absence of pulsation in the prolapsed umbilical cord is an unreliable sign of fetal death. There are many recorded instances 510 in which cord pulsations were absent but the fetal heart was audible, and in which the infants survived.

Procedures that have been used to relieve pressure on the umbilical cord as a first-aid measure pending delivery include manual elevation of the presenting part, and placing the patient in the knee-chest or Trendelenburg position. Perinatal mortality seems lower when some attempt has been made to relieve pressure on the cord. ${ }^{1}$

Fetal prognosis has improved in recent years with the more liberal use of caesarean section in place of heroic vaginal manipulations to achieve delivery through an incompletely dilated cervix. Nevertheless, the perinatal mortality rate is still around $20-30^{\prime}$, , and cord prolapse results in the loss of 600 infants annually in England and Wales. Surviving infants may also suffer late sequelae as a result of cerebral hypoxia, prematurity, and birth trauma. The incidence of these is difficult to assess, there having been few long-term follow-up studies. Cushner ${ }^{1}$ traced 63 children who had survived cord prolapse 5-25 years previously: 60 were apparently normal.

Though we can do little to prevent prolapse of the umbilical cord, emphasis must be placed on earlier diagnosis of the condition if we are to improve the appalling perinatal mortality rate. Ideally continuous fetal heart rate monitoring should be routine from the onset of labour, whether or not the membranes are ruptured. Variable decelerations and other fetal heart rate patterns have been described ${ }^{11} 12$ which are suggestive of umbilical cord compression. Recognition of these patterns may give early warning of cord complications in $90 \%$ of cases. ${ }^{11}$ Unfortunately few hospitals have sufficient equipment to monitor the fetal heart rate continuously in all labouring women, so we need to identify those patients at particular risk. The incidence of prolapsed cord may be as high as $11 \%$ in compound presentations ${ }^{9}$ and over $6 \%$ when the breech presents, ${ }^{2}$ and these malpresentations at least should therefore be regarded as indications for continuous fetal heart rate monitoring.

Cord prolapse occurs before hospital admission in up to $25 \%$ of cases. ${ }^{1313}$ Patients should therefore be encouraged to come into hospital at the first sign of labour rather than waiting until regular contractions are occurring. 
Finally, the mode of onset of labour deserves special consideration in patients with unstable lie, malpresentation, or polyhydramnios. In these circumstances there is much to commend elective amniotomy in a controlled fashion in an operating theatre rather than for the obstetrician to wait for spontaneous rupture of the membranes. If the cord is going to prolapse it is preferable that it should do so while the operator's fingers are still within the vagina. This approach also permits him to apply a monitoring electrode at the earliest possible moment.

${ }^{1}$ Cushner, I M, American fournal of (Obstetrics and Gynecology, 1961, 81, 666.

2 Savage, E W, Schuyler, G K, and Wynn, R M, Obstetrics and Gynecology, 1970, 36, 502

${ }^{3}$ Kettle, M J, British Medical Fournal, 1967, 1, 472.

4 Mengert, W F, and Longwell, F H, American fournal of Obstetrics and Gynecology, 1940, 40, 79.

5 Cope, E, Fournal of Obstetrics and Gynaecology of the British Empire, 1951, $58,259$.

${ }^{6}$ Seligman, S A, British Medical fournal, 1960, 2, 1496.

' D'Esopo, D A, Moore, D B, and Lenzi, E, American fournal of (Obstetrics and Gynecology, 1964, 89, 561 .

${ }^{8}$ Keettel, W C, Diddle, A W, and Plass, E D, American fournal of (Obstetrics and Gynecology, 1940, 40, 225.

${ }^{9}$ Migliorini, G D, and Pepperell, R J, Medical fournal of Australia, 1977, 2, 522.

${ }^{10}$ Kurzrock, J, American fournal of Obstetrics, 1932, 23, 403

11 Tejani, N A, et al, Obstetrics and Gynecology, 1977, 49, 159.

${ }^{12}$ Goldkrand, J W, and Speichinger, J P, American fournal of Obstetrics and Gynecology, 1975, 122, 144.

13 Clark, D O, Copeland, W, and Ullery, J C, American fournal of Obstetrics and Gynecology, 1968, 101, 84.

\section{Conservative treatment of rectal tumours}

The diagnosis of carcinoma of the rectum usually means that the patient will be submitted to radical surgery-an abdominoperineal excision of the rectum with a permanent colostomy, or, if the tumour is high in the rectum, conservative resection, often combined with temporary colostomy. The justification for this major and often mutilating surgery is the chance of long survival in those early cases in which there has been no dissemination to the regional lymph nodes. The excellent results of these radical operations have made surgeons less than enthusiastic about more limited procedures, for they have seen cure of the disease as more important than the burden of a permanent colostomy. Yet it is now becoming clear that local excision of some rectal cancers is justifiable. Suitable patients are, firstly, those where the local operation is all that is needed for cure, and, secondly, those whose general condition makes them unfit for major surgery.

Morson, Bussey, and Samourian have recently presented the results of "total biopsy" of selected cancers of the rectum and distal colon carried out at St Mark's Hospital over the last 25 years. ${ }^{1}$ Most of these were within reach of the sigmoidoscope, but some more proximal growths were treated by colotomy and local excision. Careful histological examination of the removed specimen included assessment of the completeness of local excision; the depth of invasion of the tumour (whether into the submucosal plane only, into the muscularis, or right across the bowel wall into the extramural tissues); and the grade of malignancy of the invasive carcinoma. The risk of lymph node metastasis having taken place is very low when direct spread is confined to the submucosal plane of the rectal wall, the only exception being in poorly differentiated adenocarcinomas. In 91 patients treated by local excision only and in whom the tumours were considered to have been completely removed on histological assessment the survival rate $\underline{\square}$ was excellent, with only three recurrences, one of which was cured by a further radical resection. At the other end of the $\stackrel{\Phi}{\perp}$ spectrum there were 23 patients in whom local excision was $\stackrel{.}{.}$ considered incomplete. Of these, 14 had no further surgical $\overrightarrow{\vec{F}}$ treatment, either because the procedure was palliative in the $\frac{9}{0}$ presence of hepatic metastases or because of their advanced age and poor general condition-but even so there were only $\frac{\bar{\omega}}{\bar{m}}$ five recurrences. A further major bowel resection was per- $\overparen{\mathbb{Q}}$ formed in the remaining nine patients but only three of the surgical specimens contained residual growth.

Reviewing their patients having local excision only with no $\vec{\circ}$ early reoperation, Lock and his colleagues ${ }^{2}$ at St Mark's found $\overrightarrow{\vec{\omega}}$ that where complete local excision was confirmed on histolo- of gical examination the crude five-year survival was $82^{\prime \prime}{ }^{\prime}$; ; where $\frac{3}{3}$ complete excision was doubtful this was $64^{\circ}{ }^{\circ}$; and where it $\overrightarrow{.}$ was incomplete $57 \%$. The corrected five-year survival rates $\stackrel{\sigma}{\rightarrow}$ in these three categories were $100^{\circ}{ }_{1}, 96^{\circ}{ }_{1}$, , and $83^{\circ}{ }_{\circ}$, res- $\vec{\omega}$ pectively.

The introduction of the colonoscope has let the surgeon $\vec{\circ}$ deal with polypoid tumours throughout the large bowel by diathermy snare removal. Fortunately, most polyps-even $\vec{\exists}$ large ones-above the rectum are pedunculated. ${ }^{3}$ Most of these prove to be benign, and indeed Williams and his col- $\frac{\bar{a}}{3}$ leagues ${ }^{4}$ found that only nine of 250 polyps removed at $\vec{\sim}$ colonoscopy proved to be carcinomatous on histological examination.

Even larger tumours, not suitable for polypectomy, may still be amenable to conservative surgery. Parks and Stuart described 30 patients with villous tumours of the rectum, four with malignant change, treated by local excision per anum. The $\frac{\circ}{\Phi}$ average diameter of the tumours was $6 \mathrm{~cm}$, and six of the patients had circumferential lesions. Three of these six $\frac{0}{3}$ patients had total papillomatosis of the rectum; in the past in such circumstances many surgeons would have excised the rectum. Local infection and incontinence were not features of this series, and in every case the sphincters were preserved. The recurrence rate was $10 \%$, but recurrences could be treated by further local excision. In the three patients with total papillomatosis, the authors described an ingenious operation: $\delta$ after local excision of the rectal mucosa the sigmoid colon was 3

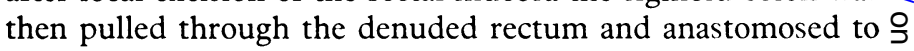
the pectinate line.

Small, mobile, non-pedunculated rectal tumours which are $D$ well differentiated may on occasion be suitable for local full $\stackrel{0}{=}$. thickness excision, either per anum or by the trans-sphincteric $\tilde{O}$ approach, which has been well described by Mason. ${ }^{6}$ Again, N this is especially indicated in patients whose age, poor general health, or obesity might contraindicate more radical surgery. 0

Local excision of cancers of the rectum requires careful $\mathbb{\Phi}$ selection and full collaboration with the histologist. In a small $\stackrel{?}{+}$ but important group of patients it will enable curative treat- $\frac{T}{0}$ ment without major surgery or the burden of a colostomy. The technique is not suitable for poorly differentiated tumours, $\frac{\Omega}{\mathbb{D}}$ and careful clinical follow-up is essential to detect and immediately treat recurrence of the disease.

\footnotetext{
${ }^{1}$ Morson, B C, Bussey, H J R, and Samourian, S, Gut, 1977, 18, 1045.

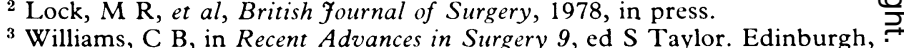
Churchill Livingstone, 1977.

4 Williams, C B, et al, British fournal of Surgery, 1974, 61, 673.

${ }^{5}$ Parks, A G, and Stuart, A E, British Fournal of Surgery, 1973, 60, 688.

${ }^{6}$ Mason, A Y, Proceedings of the Royal Society of Medicine, 1970, 63, 1259.
} 